\title{
Genetics and genomics of reproductive disorders in Canadian Holstein cattle
}

\author{
A. R. Guarini, ${ }^{1}$ D. A. L. Lourenco, ${ }^{2}$ L. F. Brito, ${ }^{1}$ M. Sargolzaei, ${ }^{1,3}$ C. F. Baes, ${ }^{1}$ F. Miglior, ${ }^{1,4}$ I. Misztal, ${ }^{2}$ \\ and F. S. Schenkel ${ }^{1 *}$ \\ ${ }^{1}$ Centre for Genetic Improvement of Livestock, Department of Animal Biosciences, University of Guelph, Guelph, ON, Canada N1G 2W1 \\ ${ }^{2}$ Department of Animal and Dairy Science, University of Georgia, Athens 30602 \\ ${ }^{3}$ The Semex Alliance, Guelph, ON, Canada N1H 6J2 \\ ${ }^{4}$ Canadian Dairy Network, Guelph, ON, Canada N1K 1E5
}

\section{ABSTRACT}

In Canada, reproductive disorders known to affect the profitability of dairy cattle herds have been recorded by producers on a voluntary basis since 2007 . Previous studies have shown the feasibility of using producer-recorded health data for genetic evaluations. Despite low heritability estimates and limited availability of phenotypic information, sufficient genetic variation has been observed for those traits to indicate that genetic progress, although slow, can be achieved. Pedigree- and genomic-based analyses were performed on producer-recorded health data of reproductive disorders, including retained placenta (RETP), metritis (METR), and cystic ovaries (CYST) using traditional BLUP and single-step genomic BLUP. Genome-wide association studies and functional analyses were carried out to unravel significant genomic regions and biological pathways, and to better understand the genetic mechanisms underlying RETP, METR, and CYST. Heritability estimates (posterior standard deviation in parentheses) were 0.02 (0.003), 0.01 (0.004), and 0.02 (0.003) for CYST, METR, and RETP, respectively. A moderate to strong genetic correlation of 0.69 (0.102) was found between METR and RETP. Averaged over all traits, sire proof reliabilities increased by approximately 11 percentage points with the incorporation of genomic data using a multiple-trait linear model. Biological pathways and associated genes underlying the studied traits were identified and will contribute to a better understanding of the biology of these 3 health disorders in dairy cattle.

Key words: dairy cattle, fertility, genetic parameters, producer-recorded data, single-step genome-wide association study (GWAS)

Received May 9, 2018.

Accepted September 29, 2018.

*Corresponding author: schenkel@uoguelph.ca
INTRODUCTION

In the past few years, several countries have started to include health traits in their selection objectives to minimize the negative impact of years of selecting only for traits related to milk production and cow conformation (Mackey et al., 2007; Berry et al., 2016; Chesnais et al., 2016). A decline in health, reproduction, and longevity has been observed in various populations and can lead to a decrease in the overall profitability of herds due to increased culling rates, veterinary expenses, replacement costs, and decreased milk sales (Pritchard et al., 2013; Parker Gaddis et al., 2014). Reproductive disorders, such as cystic ovaries (CYST), retained placenta (RETP), and metritis (METR), are known to affect the profitability of dairy farms (Kelton et al., 1998). In Canada, disease prevalences were found to be about $8.2,10.8$, and $4.6 \%$ for CYST, METR, and RETP, respectively (Koeck et al., 2012). In Nordic countries, data recording, genetic evaluations, and selection for reproduction and health traits started in the 1960s. The adoption of a selection index (Total Merit Index, TMI) that comprises not only production but also reproduction and health traits enabled those countries to improve functional efficiency of dairy cows while maintaining a steep increase in production (Philipsson and Lindhé, 2003). Recording of health traits is mandatory in the Nordic countries. In Canada, however, health data are recorded by producers using their on-farm herd management software or calendar log books (Van Doormaal, 2009). Koeck et al. (2012) demonstrated the feasibility of using producer-recorded health data for genetic evaluations in Canada, where more than $40 \%$ of all dairy producers under milk recording also participate in the health-recording system. The use of dense genomic marker data has been widely adopted in many species (Meuwisssen et al., 2016) and has been proven to overcome the limitations of traditional breeding programs and progeny test schemes, such as the high cost and time associated with proving a bull and long generation intervals (Schaeffer, 2006; 
Table 1. Summary statistics for health disorders in first-lactation Canadian Holstein cows

\begin{tabular}{lccccc}
\hline Trait & $\begin{array}{c}\text { Incidence } \\
(\%)\end{array}$ & $\begin{array}{c}\text { Days from } \\
\text { calving }\end{array}$ & $\begin{array}{c}\text { No. of } \\
\text { records }\end{array}$ & $\begin{array}{c}\text { No. of } \\
\text { year-seasons }\end{array}$ & $\begin{array}{c}\text { No. of } \\
\text { herd-years }\end{array}$ \\
\hline Cystic ovaries & 3.2 & 0 to 305 & 185,258 & 42 & 5,685 \\
Metritis & 4.4 & 0 to 150 & 143,936 & 42 & 3,238 \\
Retained placenta & 2.8 & 0 to 14 & 205,079 & 42 & 5,511 \\
\hline
\end{tabular}

Dekkers, 2007; Hayes et al., 2009). In North America, the implementation of a genetic-based selection program for novel traits, such as reproductive disorders, is under implementation and actively investigated. For instance, official genetic evaluations for mastitis resistance and metabolic disease resistance became available in Canada in 2014 and 2016, respectively. Two recent studies (Parker Gaddis et al., 2014; Vukasinovic et al., 2017) applied a single-step genomic BLUP (ssGBLUP) procedure for evaluation of health traits in dairy cattle based on on-farm recorded information. The authors concluded that genetic selection for those traits using data recorded by producers is feasible, and an increase in reliability was observed with the inclusion of genomic information. The ssGBLUP approach that combines genotypes, pedigree, and phenotypes into a single evaluation (Misztal et al., 2009; Aguilar et al., 2010; Christensen and Lund, 2010) has become routine in various breeding schemes. By replacing the pedigree-based relationship matrix $(\mathbf{A})$ with the augmented $\mathbf{H}$ matrix to include genomic information, both genotyped and nongenotyped animals can be included simultaneously in the evaluation.

Because the number of individuals with producerrecorded data for reproductive disorder traits and genomic information is scarce, using all sources of information (i.e., genotypes and pedigree and phenotypes for both genotyped and nongenotyped animals) simultaneously may be of great value when performing genetic analyses. The objectives of the current study were to (1) perform pedigree- and genomic-based analyses of RETP, METR, and CYST, using traditional BLUP and ssGBLUP; (2) perform genome-wide association study (GWAS) analysis to prospect significant genomic regions and biological pathways associated with the 3 reproductive disorders; and (3) explore the genetic mechanisms underlying the studied traits.

\section{MATERIALS AND METHODS}

\section{Data}

Database. Reproductive disorder records taken between April 1, 2007, and March 31, 2017, were obtained from the Canadian Dairy Network (CDN, Guelph, ON, Canada; www.cdn.ca) and included events for CYST,
METR, and RETP from first-lactation Holstein cows. Table 1 shows a descriptive analysis and summary of the data structure by trait.

Genomic data from 33,575 Holstein bulls, born between 1960 and 2015 and genotyped with the Illumina Bovine SNP50 BeadChip (50K, Illumina Inc., San Diego, CA) or a higher density (HD) panel were also available for this study. For the animals genotyped with the HD panel, the SNP present in the HD panel that overlapped with the $50 \mathrm{~K}$ panel were kept and the remaining missing $50 \mathrm{~K}$ panel markers were imputed using the FImpute software (Sargolzaei et al., 2014). In addition, 6,842 Holstein cows born between 1997 and 2015 genotyped with either the $50 \mathrm{~K}$ panel or a low-density panel (6K) and then accurately imputed (Larmer et al., 2014) to the 50K panel using the FImpute software (Sargolzaei et al., 2014) were available for analyses. Genotypes were coded as 0,1 , or 2 for calculation of the genomic relationship matrix $(\mathbf{G})$. Monomorphic SNP, animals with genotype call rates less than 90\%, SNP with call rates less than 90\%, SNP that were out of Hardy-Weinberg equilibrium with very low probability $\left(P\right.$-value $\left.<10^{-6}\right)$ or with minor allele frequency $<0.05$, and individuals with parent-progeny Mendelian conflicts were excluded from the analysis. After quality control, the number of genotyped individuals was 40,412, and the final genomic data included 40,852 SNP. The PREGSF90 software was used for SNP and sample quality control (Misztal et al., 2002).

Data Validation and Editing. To ensure that all cows were from herds with reliable recording, several editing criteria were applied separately for each disease. Only herds having at least 2 records (i.e., occurrence of a disorder reported by the farmer) of a specific disease were considered. The first and last records in each herd had to be at least $180 \mathrm{~d}$ apart. This was performed to remove herds that had recorded for only a short time period. A minimum disease frequency of $1 \%$ for all traits was applied to ensure continuous data recording within individual herds. Only records from cows with age at first service between 19 and 43 mo were considered.

Trait Definitions. Reproductive disorders were defined as binary traits $(0=$ no case, $1=$ at least one case) based on whether or not the cow had at least one disease case recorded within the first $305 \mathrm{~d}$ after calving 
for CYST, within $150 \mathrm{~d}$ after calving for METR, and within $14 \mathrm{~d}$ after calving for RETP.

\section{Variance Component Estimation}

Both single- and multi-trait linear models were used for analyses of CYST, METR, and RETP and the results were compared. Despite the binary nature of the studied traits, previous studies have shown that the use of threshold models did not improve the goodness of fit compared with linear models (e.g., Neuenschwander et al., 2012). Thus, following the current genetic evaluation models used in Canada, a linear model was applied. For multiple-trait analysis, a cow was allowed to have only one missing record. Variance components were estimated using either the pedigree-based relationship matrix (A) or the $\mathbf{H}$ matrix, a modified genetic relationship matrix that combines $\mathbf{A}$ and genomic-based (G) relationship matrices for all traits, applying the model described below using the GIBBS2F90 software from the BLUPF90 family (Misztal et al., 2002). A total of 200,000 iterations were completed with the first 50,000 discarded as burn-in, saving 1 every 25 samples. Post-Gibbs analyses were performed using the POSTGIBBSF90 software (Misztal et al., 2002). Trace plots were inspected visually to ensure that convergence had been reached. Posterior standard deviations were calculated for each estimate. The model equation used for each trait was

$$
\mathbf{y}=\mathbf{X} \boldsymbol{\beta}+\mathbf{Z}_{\mathrm{h}} \mathbf{h}+\mathbf{Z}_{\mathrm{a}} \mathbf{a}+\mathbf{e},
$$

where $\mathbf{y}$ is a vector of observations for the disease trait; $\boldsymbol{\beta}$ is a vector of systematic effects, including fixed effects of age at calving and year-season of calving; $\mathbf{h}$ is a vector of random herd-year of calving effects, where $\mathbf{h} \sim N\left(0, \mathbf{I} \sigma_{h}^{2}\right)$, with $\sigma_{h}^{2}$ the herd-year of calving variance; $\mathbf{a}$ is a vector of random additive genetic effects, where $\mathbf{a} \sim N\left(0, \mathbf{H} \sigma_{a}^{2}\right)$, with $\sigma_{a}^{2}$ the additive genetic variance; $\mathbf{e}$ is a vector of random errors, where $\mathbf{e} \sim N\left(0, \mathbf{I} \sigma_{e}^{2}\right)$, with $\sigma_{e}^{2}$ the error variance; and $\mathbf{X}, \mathbf{Z}_{\mathrm{h}}$, and $\mathbf{Z}_{\mathrm{a}}$ are the corresponding incidence matrices. Eight classes of age at calving $(\leq 22,23,24,25,26,27,28-29$, and $\geq 30 \mathrm{mo})$ and 4 seasons of calving (January to March, April to June, July to September, and October to December) were defined. For the multiple-trait analysis, the covariance structure among traits was modeled as

$$
\operatorname{Var}\left[\begin{array}{l}
\mathbf{h} \\
\mathbf{a} \\
\mathbf{e}
\end{array}\right]=\left[\begin{array}{ccc}
\mathbf{I} \otimes \mathbf{H}_{0} & \mathbf{0} & \mathbf{0} \\
& \mathbf{A} \otimes \mathbf{G}_{0} & \mathbf{0} \\
\text { symm. } & & \mathbf{I} \otimes \mathbf{R}_{0}
\end{array}\right],
$$

where

$$
\mathbf{H}_{0}=\left[\begin{array}{ccc}
\sigma_{h 1}^{2} & \sigma_{h 1 h 2} & \sigma_{h 1 h 3} \\
& \sigma_{h 2}^{2} & \sigma_{h 2 h 3} \\
\text { symm. } & & \sigma_{h 3}^{2}
\end{array}\right]
$$

is the (co)variance matrix between traits due to random herd-year of calving effects; $\mathbf{I}$ is an identity matrix;

$$
\mathbf{G}_{0}=\left[\begin{array}{ccc}
\sigma_{a 1}^{2} & \sigma_{a 1 a 2} & \sigma_{a 1 a 3} \\
& \sigma_{a 2}^{2} & \sigma_{a 2 a 3} \\
\text { symm. } & & \sigma_{a 3}^{2}
\end{array}\right]
$$

is the (co)variance matrix between traits due to animal additive genetic effects; $\mathbf{A}$ is the additive genetic relationship matrix; and

$$
\mathbf{R}_{0}=\left[\begin{array}{ccc}
\sigma_{e 1}^{2} & \sigma_{e 1 e 2} & \sigma_{e 1 e 3} \\
& \sigma_{e 2}^{2} & \sigma_{e 2 e 3} \\
\text { symm. } & & \sigma_{e 3}^{2}
\end{array}\right]
$$

is the (co)variance matrix between traits due to random error effects.

\section{Genomic Prediction of Breeding Values}

By using the same models described above, genomic information was incorporated using the ssGBLUP approach and results were compared. The ssGBLUP method replaces the traditional $\mathbf{A}$ matrix by the $\mathbf{H}$ matrix (Legarra et al., 2009; Aguilar et al., 2010). The inverse of $\mathbf{H}$ is represented by

$$
\mathbf{H}^{-1}=\mathbf{A}^{-1}+\left[\begin{array}{cc}
\mathbf{0} & \mathbf{0} \\
\mathbf{0} & \left(\mathbf{G}^{-1}-\mathbf{A}_{22}^{-1}\right)
\end{array}\right],
$$

where $\mathbf{G}$ was created as $0.95 \mathbf{G}^{*}+0.05 \mathbf{A}_{22}$ (to avoid singularity problems), $\mathbf{A}_{22}$ is the pedigree relationship matrix among genotyped animals, and $\mathbf{G}^{*}$ was constructed as in VanRaden (2008):

$$
\mathbf{G}^{*}=\frac{\mathbf{Z D Z}^{\prime}}{2 \sum p_{i}\left(1-p_{i}\right)},
$$

where $\mathbf{Z}$ is a matrix of centered SNP content; $\mathbf{D}$ is a diagonal matrix of SNP variance; and $p_{i}$ is the minor allele frequency of SNP $i$. 
The GIBBS2F90 software (Misztal et al., 2002) was used for the analyses. The genomic estimated breeding values (GEBV) were obtained by solving the mixed model equations using GIBBS2F90, using 5,000 iterations with the first 1,000 discarded as burn-in, saving 1 every 25 samples, with fixed variance components from the previously described analysis. Approximate reliabilities of the EBV and GEBV were calculated as $1-P E V_{j} /\left(1+f_{j}\right) \sigma_{g}^{2}$, where $1+f_{j}$ is the diagonal element of $\mathbf{A}, \sigma_{g}^{2}$ is the genetic variance for a given trait, and $P E V_{j}$ is the prediction error variance for animal $j$, obtained based on the SD of EBV or GEBV. Under the assumptions of normality and known covariance structure of the model, posterior variances of the EBV are the variances of prediction error (Jamrozik et al., 2000; Sorensen and Gianola, 2002). Therefore, for sake of calculating the reliability of the predictions, the SD of EBV or GEBV was used as their SE.

\section{GWAS}

Genome-wide association analyses for CYST, METR, and RETP were performed using a weighted ssGWAS (WssGWAS) approach considering a multiple-trait linear model, as described above. Following ideas presented by Nagamine et al. (2002) for detection of QTL, Wang et al. (2012) showed that the concept of GBLUP being equivalent to SNP-BLUP could be extended to the ssGBLUP approach. VanRaden (2008) showed that from the selection index equation for GBLUP:

$$
\hat{\mathbf{a}}=\mathbf{G}\left[\mathbf{G}+\mathbf{R}\left(\sigma_{a}^{2} / \sigma_{e}^{2}\right)\right]^{-1}(\mathbf{y}-\mathbf{X} \hat{\mathbf{b}}),
$$

where $\hat{\mathbf{a}}$ is GEBV and $\mathbf{R}$ is a diagonal matrix accounting for heterogeneous residual variance. If $\hat{\mathbf{a}} \mid \hat{\mathbf{u}}=\mathbf{Z} \hat{\mathbf{u}}$, replacing the leftmost $\mathbf{G}$ by $\mathbf{Z}^{\prime}$, and weighting by the ratio of SNP to additive direct variances would allow the calculation of SNP effects $(\hat{\mathbf{u}})$ :

$$
\hat{\mathbf{u}}=\mathbf{Z}^{\prime} \lambda\left[\mathbf{G}+\mathbf{R}\left(\sigma_{a}^{2} / \sigma_{e}^{2}\right)\right]^{-1}(\mathbf{y}-\mathbf{X} \hat{\mathbf{b}}),
$$

where $\lambda$ is $\sigma_{u}^{2} / \sigma_{a}^{2}$, and $\sigma_{u}^{2}$ is the SNP variance. We can assume that $\sigma_{u}^{2}=\sigma_{a}^{2} / 2 \sum p_{i}\left(1-p_{i}\right)$. Therefore, $\lambda$ can be reduced to $1 / 2 \sum p_{i}\left(1-p_{i}\right)$.

Assuming that $\mathbf{w}=\left[\mathbf{G}+\mathbf{R}\left(\sigma_{a}^{2} / \sigma_{e}^{2}\right)\right]^{-1}(\mathbf{y}-\mathbf{X} \hat{\mathbf{b}})$ and $\hat{\mathbf{u}}=\lambda \mathbf{Z}^{\prime} \mathbf{w}$, then $\hat{\mathbf{a}}=\mathbf{G} \mathbf{w}$. In this way, $\mathbf{w}=\mathbf{G}^{-1} \hat{\mathbf{a}}$, and finally, the SNP effects can be calculated as $\hat{\mathbf{u}}=\lambda \mathbf{Z}^{\prime} \mathbf{G}^{-1} \hat{\mathbf{a}}$, as $\operatorname{Var}(\mathbf{u})=\mathbf{D}$, the conditional mean of SNP effects given the GEBV is $\hat{\mathbf{u}} \mid \hat{\mathbf{a}}=\lambda \mathbf{D Z} \mathbf{G}^{-1} \hat{\mathbf{a}}$. Thus, given that GEBV from ssGBLUP were available, SNP effects were calculated as (Wang et al., 2012) $\hat{\mathbf{u}}=\lambda \mathbf{D Z}^{\prime} \mathbf{G}^{-1} \hat{\mathbf{a}}$. Estimates of SNP effects were then used to calculate individual variance of each SNP effect (Zhang et al., 2010): $\sigma_{u, i}^{2}=\left\{d_{i i}\right\}=\hat{u}_{i}^{2} 2 p_{i}\left(1-p_{i}\right)$.

Weighted ssGWAS is an iterative process with several steps (Wang et al., 2012); considering $t$ as the iteration number, the steps are:

1. $t=0 ; \mathbf{D}_{t}=\mathbf{I} ; \mathbf{G}_{(t)}=\mathbf{Z D}_{(t)} \mathbf{Z}^{\prime} \lambda$;

2. GEBV for all animals in data set are estimated using ssGBLUP;

3. SNP effects are obtained as $\hat{\mathbf{u}}_{(t)}=\lambda \mathbf{D}_{(t)} \mathbf{Z}^{\prime} \mathbf{G}_{(t)}^{-1} \hat{\mathbf{a}}_{g}$;

4. SNP variances are calculated as $d_{i(t+1)}^{*}=\hat{\mathbf{u}}_{(i t)}^{2} 2 p_{i}\left(1-p_{i}\right)$;

5. SNP values are normalized so additive genetic variance remains constant, where $t r$ is the trace of the matrix:

$$
\mathbf{D}_{(t+1)}=\frac{\operatorname{tr}\left(\mathbf{D}_{(0)}\right)}{\operatorname{tr}\left(\mathbf{D}_{(t+1)}^{*}\right)} \mathbf{D}_{(t+1)}^{*} ;
$$

6. Computed: $\mathbf{G}_{(t+1)}^{*}=\mathbf{Z D}_{(t+1)} \mathbf{Z}^{\prime} \lambda$;

7. $t=t+1$;

8. Loop to step 2.

In the present study, we obtained the effects of markers after iterating steps 2 to 6 three times. This procedure was repeated for 3 iterations based on the realized accuracies of GEBV according to Legarra et al. (2008) and performed by Wang et al. (2014) and findings from Zhang et al. (2016). The variance explained by 20-SNP moving windows was successively calculated across the whole genome. Thus, the percentage of genetic variance explained by the $i$ th window was

$$
\frac{\operatorname{var}\left(a_{i}\right)}{\sigma_{a}^{2}}=\frac{\operatorname{var}\left(\sum_{j=i}^{20} \mathbf{z}_{j} \hat{u}_{j}\right)}{\sigma_{a}^{2}},
$$

where $a_{i}$ is the genetic value of the $i$ th window, $\sigma_{a}^{2}$ is the total genetic variance, $\mathbf{z}_{j}$ is a vector of SNP content of the $j$ th SNP for all individuals, and $\hat{u}_{j}$ is the marker effect within the $i$ th region.

\section{Functional Analyses}

Genomic windows that explained more than $1 \%$ of the total genetic additive variance were further investigated. Genes located within those windows were mapped using the bovine genome assembly UMD3.1 (release 90; http://www.ensembl.org/Bos_taurus/Info/ 
Table 2. Heritability estimates (in bold on the diagonal, with posterior SD in parentheses), genetic correlations (above diagonal, with posterior SD in parentheses), and phenotypic correlations (below diagonal) from multipletrait analysis of first-lactation Holstein cows

\begin{tabular}{llcc}
\hline Trait & Cystic ovaries & Metritis & Retained placenta \\
\hline Cystic ovaries & $\mathbf{0 . 0 2}(\mathbf{0 . 0 0 3})$ & $0.38(0.174)$ & $0.32(0.119)$ \\
Metritis & 0.05 & $\mathbf{0 . 0 1}(\mathbf{0 . 0 0 4})$ & $0.69(0.102)$ \\
Retained placenta & 0.03 & 0.13 & $\mathbf{0 . 0 2}(\mathbf{0 . 0 0 3})$ \\
\hline
\end{tabular}

Index) and considered for functional analysis. Bos taurus nucleotide and protein sequences of the genes located within windows that explained more than $1 \%$ of the total genetic variance were downloaded from the ENSEMBL Biomart Martview application (www .ensembl.org/biomart/martview). All unique sequences were aligned against the sequences in the National Center for Biotechnology Information (NCBI; www .ncbi.nlm.nih.gov) nonredundant (NR) database using the BLASTx and BLASTp algorithms from the Blast2GO software (Götz et al., 2008). Sequences with a BLAST match were mapped and annotated. Metabolic pathways associated with significant sequences were identified using the Kyoto Encyclopedia of Genes and Genomes (KEGG; Kanehisa and Goto, 2000; Kanehisa et al., 2016, 2017).

\section{RESULTS AND DISCUSSION}

\section{Heritabilities and Genetic and Phenotypic Correlations}

Incidences for each trait during first lactation were 3.6, 4.4, and $2.8 \%$ for CYST, METR, and RETP, respectively (Table 1). All incidences found in the present study were within the range reported in literature (e.g., Kelton et al., 1998; Parker Gaddis et al., 2012; Dhakal et al., 2015). Heritability estimates and genetic correlations (posterior means and standard errors) obtained with a multiple-trait linear model are shown in Table 2. Heritability estimates obtained from multiple-trait analyses were similar to those obtained with single-trait analyses (results not shown) and in accordance with previous studies that also used producer-recorded data from Holstein cows in Canada (Koeck et al., 2012; Jamrozik et al., 2016). In general, most studies reported heritability estimates for health traits lower than $10 \%$ and, although environmental factors play a large role in such diseases, there is still a genetic component associated with them, which implies that improvement can be achieved through selection. Moreover, all studied traits displayed moderate to strong, positive (favorable) genetic correlations. Therefore, selection to improve one trait will potentially lead to a favorable response in others (Table 2). The strongest genetic correlation was found between RETP and METR (0.69 \pm 0.102; Table 2 ), which is in accordance with previous studies (e.g., Koeck et al., 2012; Parker Gaddis et al., 2014; Jamrozik et al., 2016). Dhakal et al. (2015) reported a significant positive recursive effect from liability of RETP on liability of METR and, although no direct effects were found from the studied health disorders on milk yield, a strong causal relationship was observed between health disorders and culling, which causes economic losses.

\section{Prediction of Breeding Values}

Tables 3 and 4 show the reliabilities of sire EBV computed with pedigree and genomic information for single- and multiple-trait analyses, respectively. Multiple-trait analysis utilizes more information to evaluate the animals and therefore leads to higher reliabilities of EBV for the traits being evaluated (Schaeffer, 1984). Moreover, increased reliabilities are obtained with a reduction of prediction error variance (PEV), which is dependent on the absolute difference between error and genetic correlations; that is, greater absolute difference leads to greater accuracies for both traits (Schaeffer, 1984). In the present study, reliabilities of sire EBV were, averaged over all 3 traits, 9 percentage points higher when using a multiple-trait analysis than with single-trait analyses (Tables 3 and 4).

An improvement in reliabilities of sire EBV for all 3 traits was observed when genomic information was included in the analysis, as shown in Tables 3 and 4 for single- and multiple-trait analyses, respectively. The increase in mean reliability, calculated as the difference in overall mean reliability between genomic- and pedigree-based models, was 9,7 , and 10 percentage points for CYST, METR, and RETP, respectively, using a multiple-trait analysis (Table 4). Results from singletrait analyses were very similar but slightly higher $(11,8$, and 12 percentage points respectively; Table 3$)$, likely because the single-trait EBV were less accurate than the multiple-trait EBV and, therefore, benefited more from the use of genomic information. Increases in reliability by adding genomic information varied among sires. Figure 1 shows a trend in increase based on the number of daughters for each sire for CYST, as an example. Most often, sires with a larger number of 
Table 3. Mean reliability of sire EBV (number of sires in parentheses) computed with pedigree and genomic information for first-lactation records using single-trait analyses

\begin{tabular}{|c|c|c|c|c|c|c|c|}
\hline Trait & \multicolumn{3}{|c|}{ Pedigree information } & \multicolumn{3}{|c|}{ Genomic information } & $\begin{array}{l}\text { Overall } \\
\text { gain }^{1}\end{array}$ \\
\hline Metritis & $0.40(7,501)$ & $0.37(5,037)$ & $0.45(2,464)$ & 0.48 & 0.46 & 0.54 & 0.08 \\
\hline Retained placenta & $0.21(8,515)$ & $0.16(5,058)$ & $0.29(3,457)$ & 0.33 & 0.26 & 0.43 & 0.12 \\
\hline
\end{tabular}

${ }^{1}$ Increase in mean reliability calculated as the difference in overall mean reliability between genomic- and pedigree-based models.

daughters already have enough information to attain higher reliabilities of EBV, whereas greater benefits arising from the inclusion of genomic information are observed for sires with only a few daughters. This trend was similar for the other traits. The average number of daughters per sire was approximately 23, 19, and 24 for CYST, METR, and RETP, respectively.

As shown in Tables 3 and 4, the average proportional gains in reliability by moving from EBV to GEBV for sires with $\geq 10$ daughters and sires with $<10$ daughters across the 3 traits for single-trait analyses were 40 and $50 \%$, respectively. The same features were 24 and $30 \%$ for multivariate analyses, respectively. These average proportional gains in reliability were expected; that is, a higher proportional gain in reliability by using genomic information for bulls with fewer daughters with records and, on average, lower traditional EBV reliabilities.

The percentage of affected daughters of all sires with $\geq 10$ daughters and the best (top 10\%) and worst (bottom 90\%) sires, according to their GEBV for CYST, METR, and RETP, were calculated (Table 5). A difference among the best and worst sire categories is expected and indicates that, despite the low heritability for such traits, sufficient genetic variation for these traits exists to be useful in breeding programs aiming to genetically improve health traits. For all 3 traits, differences between the percentages of daughters affected for each sire group were observed. For instance, 1 of 18 daughters of the worst bulls developed RETP, whereas the incidence was of only 1 of 42 daughters for the best sires (Table 5).
Reliabilities of genomic predictions depend on the level of linkage disequilibrium between the markers and the QTL, the distribution of QTL effects, the heritability of the trait being evaluated, and the size of the training population from which SNP effects are obtained (Hayes et al., 2009). For lowly heritable traits, a large number of animals with phenotypes and genotypes is required to achieve reliabilities of GEBV comparable to those of traits with higher heritabilities, such as production. For instance, more phenotypic records available means more observations per SNP allele, which will lead to higher accuracies of genomic selection (Hayes et al., 2009). However, obtaining a large number of animals with both phenotypes and genotypes can be a challenge for those traits. The advantages of augmenting the genotypic data with information from phenotypes from the complete population through an ssGBLUP approach are therefore greater for lowly heritable traits (Chen et al., 2011). In addition, as shown in the present and other studies (e.g., Sun et al., 2010; Chen et al., 2011), adoption of a multiple-trait model will likely result in increased accuracy compared with those of single-trait analysis. A multiple-trait model can be easily implemented through ssGBLUP.

\section{GWAS and Functional Analyses}

Various GWAS methods have already been described in the literature (e.g., Hayes, 2013; Feng, 2014). In one of these methods, known as classical GWAS, SNP are fitted, one at a time, as a fixed effect in the model.

Table 4. Mean reliability of sire EBV computed with pedigree and genomic information for first-lactation records using multiple-trait analysis

\begin{tabular}{|c|c|c|c|c|c|c|c|}
\hline \multirow[b]{2}{*}{ Trait } & \multicolumn{3}{|c|}{ Pedigree information } & \multicolumn{3}{|c|}{ Genomic information } & \multirow[b]{2}{*}{$\begin{array}{l}\text { Overall } \\
\text { gain }^{3}\end{array}$} \\
\hline & $\begin{array}{c}\text { Overall } \\
\text { mean }\end{array}$ & $\begin{array}{c}\text { Sires < } 10 \\
\text { daughters }^{1}\end{array}$ & $\begin{array}{c}\text { Sires } \geq 10 \\
\text { daughters }\end{array}$ & $\begin{array}{l}\text { Overall } \\
\text { mean }\end{array}$ & $\begin{array}{l}\text { Sires < } 10 \\
\text { daughters }\end{array}$ & $\begin{array}{l}\text { Sires } \geq 10 \\
\text { daughters }\end{array}$ & \\
\hline Cystic ovaries & 0.32 & 0.30 & 0.37 & 0.41 & 0.39 & 0.47 & 0.09 \\
\hline Metritis & 0.48 & 0.46 & 0.52 & 0.55 & 0.54 & 0.60 & 0.07 \\
\hline Retained placenta & 0.27 & 0.24 & 0.35 & 0.37 & 0.34 & 0.45 & 0.10 \\
\hline
\end{tabular}

${ }^{1} \mathrm{n}=4,516$

${ }^{2} \mathrm{n}=1,693$.

${ }^{3}$ Increase in mean reliability calculated as the difference in overall mean reliability between genomic- and pedigree-based models. 
Table 5. Percentage of affected daughters of all sires, ${ }^{1}$ top $10 \%$ sires, and bottom $90 \%$ sires according to their genomic EBV for cystic ovaries, metritis, and retained placenta from single-trait analyses of first-lactation Holstein cows

\begin{tabular}{|c|c|c|c|c|}
\hline \multirow[b]{2}{*}{ Trait } & \multirow{2}{*}{$\begin{array}{c}\text { No. of } \\
\text { sires }\end{array}$} & \multicolumn{3}{|c|}{ Percentage of affected daughters } \\
\hline & & All & Top $10 \%$ & Bottom $90 \%$ \\
\hline Cystic ovaries & 3,120 & 7.4 & 4.7 & 7.8 \\
\hline Metritis & 2,464 & 7.7 & 4.5 & 8.2 \\
\hline Retained placenta & 3,457 & 5.2 & 2.4 & 5.7 \\
\hline
\end{tabular}

${ }^{1}$ Only sires with at least 10 daughters were considered in the calculations.

A SNP is considered significantly associated with the trait of interest if its $P$-value is below a defined significance threshold (Hayes, 2013). However, by fitting one SNP at a time, many thousands of tests are run, which can cause a multiple testing problem, although multiple testing correction methods can partially solve this issue. Moreover, finding causative mutations is a difficult task given the fact that, due to the extensive LD in dairy cattle, even SNP positioned far away from QTL may have significant effects (Pryce et al., 2010). Another method, which follows a Bayesian approach, fits all SNP simultaneously as random effects, with different prior assumptions on the distribution of possible SNP effects (Hayes, 2013). Yet, a potential issue associated with this method is that when markers are closely linked, existing effects may be split among all the other markers $(\mathrm{Xu}, 2003)$. Thus, an approach that takes into account the variance explained by specific genomic regions, instead of single SNP, is needed. Those methods mentioned above include solely individuals with both phenotypes and genotypes; therefore, to enable incorporating phenotypes from nongenotyped individuals, they require the use of pseudo-phenotypes, such as deregressed EBV. A multi-step approach can lead to increased biases and losses of accuracy (Legarra et al., 2014), thus reducing the contribution of genomic information to the detection of important genomic regions associated with the trait of interest.

In the present study, WssGWAS was implemented as an alternative GWAS method to uncover genomic regions associated with fertility disorders. The WssGWAS allows for unequal variances of markers, rather than assuming they all follow the same Gaussian distribution, which may not be a realistic assumption (Zhang et al., 2016). The use of a weighted approach for association analyses, as implemented in WssGWAS,

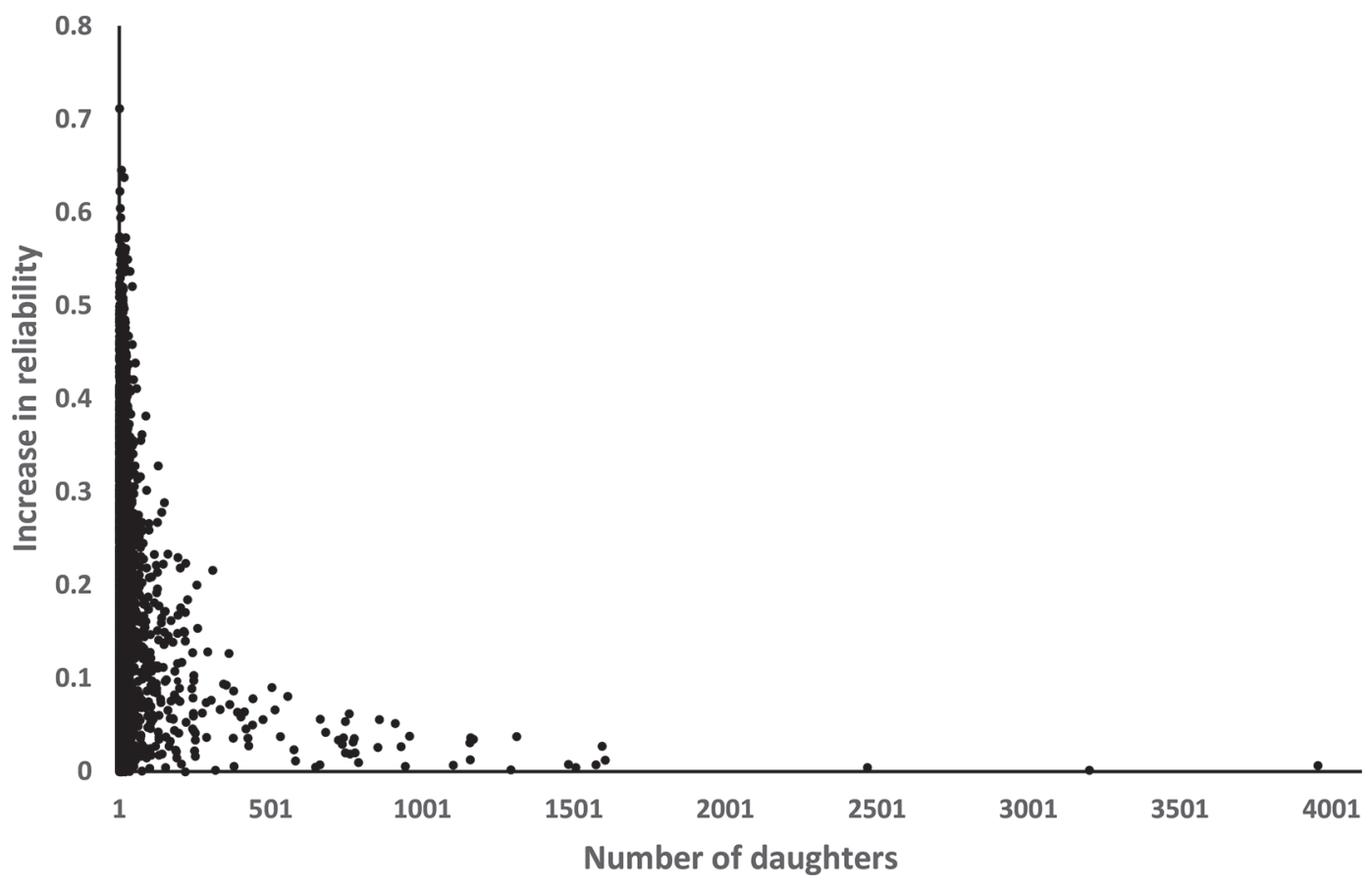

Figure 1. Increase in reliability of predictions when adding genomic information plotted against number of daughters for each sire in singlestep analysis for cystic ovaries. 
can be advantageous for small genotyped populations, leading to greater power of estimating QTL effects and positions compared with other methods. However, the benefits are offset when more animals are genotyped. Moreover, as the number of QTL controlling a trait increases (polygenic traits), accuracies obtained with WssGWAS become similar to those obtained with ssGWAS (Lourenco et al., 2017). In addition, one drawback of ssGWAS approaches is the inability to determine SNP significance levels (Wang et al., 2012). Despite that, various important genomic regions have been unraveled by using this method in a variety of traits in cattle (Barreto Amaral Teixeira et al., 2017; Medeiros de Oliveira Silva et al., 2017; Melo et al., 2017), aquaculture (Vallejo et al., 2017), and pigs (Wu et al., 2018).

Analyses were performed considering 20-SNP moving windows, which are expected to reduce the noise arising from over- or underestimation of window variances, given that a fixed number of SNP might not match haplotype blocks patterns (Wang et al., 2014). The Manhattan plots of additive genetic variance explained by 20-SNP moving windows for CYST, METR, and RETP are shown in Figures 2, 3, and 4, respectively. As expected, the results found in this study support the polygenic nature of the studied traits, with many regions across the genome having small contributions to the total genetic variation. However, some chromosomal regions appeared to have a larger contribution to the total genetic variation. Thus, windows that explained more than $1 \%$ of the variance for each trait were identified and genes located within those regions were selected for further investigation (Table 6). When combined, those regions explained 8.7, 12.6, and $10.7 \%$ of the total genetic variance for CYST, METR, and RETP, respectively. Biological pathways known to be related to CYST, METR, and RETP are shown in Table 7.

Two important biological pathways identified"cysteine and methionine metabolism" and "nicotinate and nicotinamide metabolism" - were found to be related to oxidative stress in mammals (Sordillo and Aitken, 2009; Martínez et al., 2017). Oxidative stress can cause damage to macromolecules and cells of an organism as a result of an unbalanced production of reactive oxygen species and antioxidant defenses (Gonsette, 2008; Martínez et al., 2017). This phenomenon plays an important role in the susceptibility of dairy cows to health disorders, such as mastitis, mammary edema, METR, and RETP, especially during periods of physiological, metabolic, and endocrine changes, such as those in the periparturient period and early lactation (Sordillo and Aitken, 2009).

Cows intensively selected for higher milk production are more likely to have increased incidence of health disorders (Walsh et al., 2011). Tsuruta et al. (2017) identified a major effect around the location of the DGAT1 gene on BTA14 for milk yield and mortal-

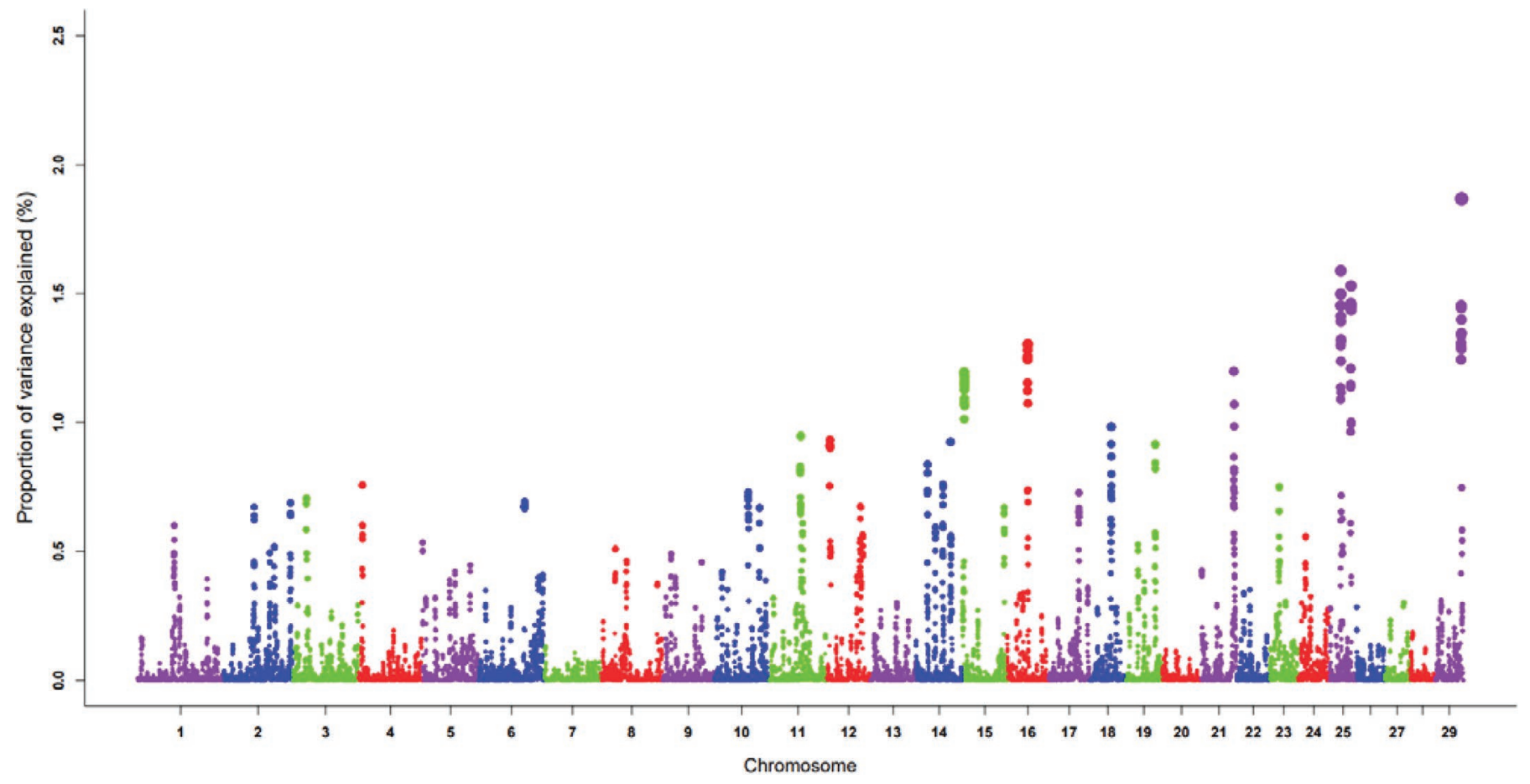

Figure 2. Manhattan plot for the proportion of genetic variance explained by the 20-SNP moving windows for cystic ovaries. 


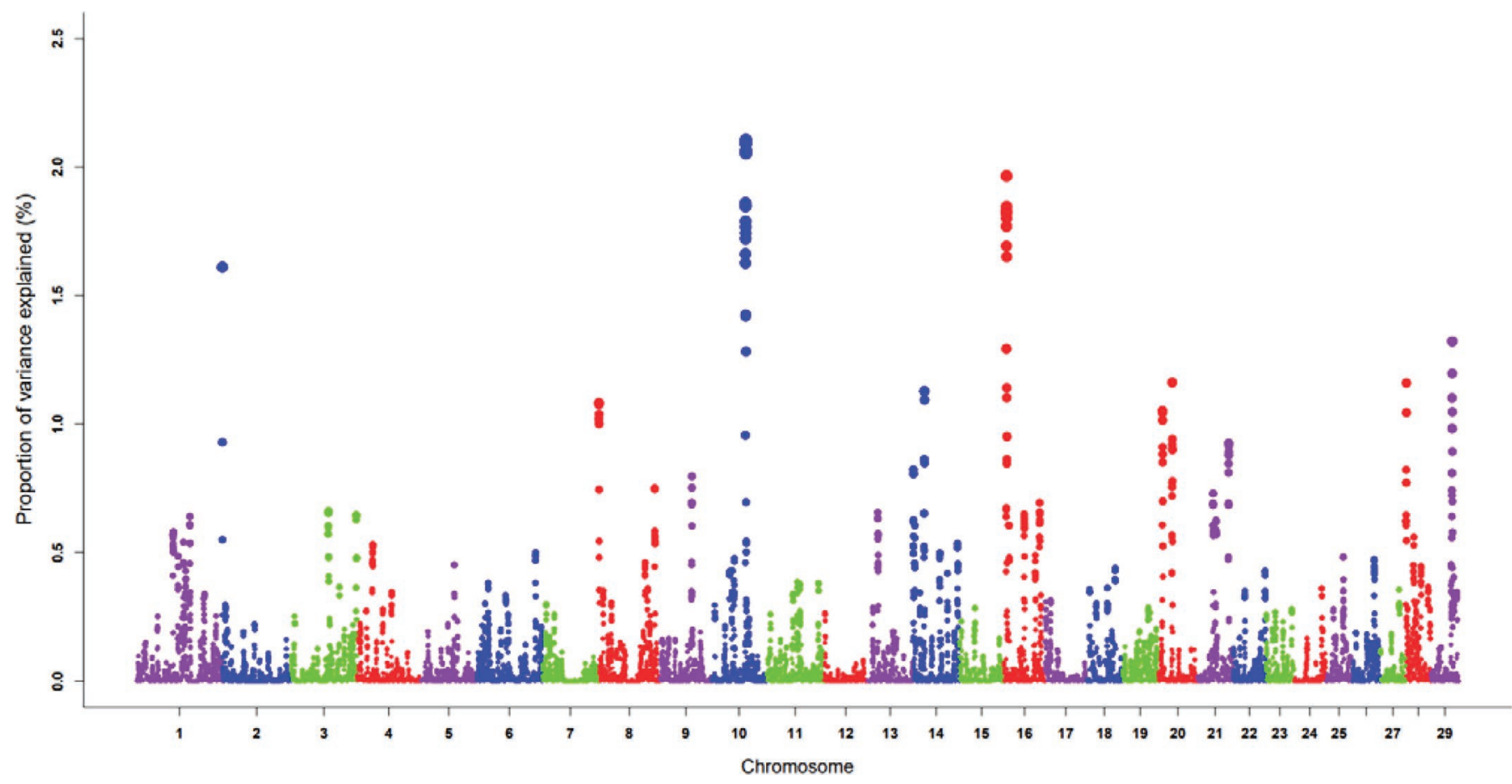

Figure 3. Manhattan plot for the proportion of genetic variance explained by the 20-SNP moving windows for metritis.

ity for US Holsteins, implying that regions affecting production have a negative effect on cow survival and longevity. During early and peak lactation, daily energy requirements of a cow exceed daily energy availability, a phenomenon known as negative energy balance (NEB). This is especially true for high-milkproducing cows (Tetens et al., 2013). During periods of $\mathrm{NEB}$, there is an increased production of nonesterified fatty acids, which are reported to be associated with increased risk for displaced abomasum, clinical ketosis, RETP, and METR during the first 30 DIM (Ospina et al., 2010). Corroborating these findings, Tetens et al. (2013) reported a significant association between NEB and the "fructose and mannose metabolism" pathway, which was also significantly associated with METR in the present study. This pathway was associated with the PFKFB2 gene, a mediator in glycolysis located on BTA16. The expression of PFKFB2 has been reported to be upregulated in the endometrium of heifers with embryos exhibiting retarded development and hence might be linked to subfertility in heifers (Beltman et al., 2010).

Dysfunctions in the "glyoxylate and dicarboxylate metabolism" and the "citrate cycle (TCA cycle)," which were significantly associated with CYST and METR, have been reported as being highly associated with early pregnancy loss in ewes (Zhao et al., 2015). Those authors also identified malfunctioning proteins that are essential for the establishment of pregnancy in the endometrium of ewes that failed to conceive. One of these proteins was malate dehydrogenase (MDH2), which was present in most pathways associated with CYST in the present study. In an earlier study, polycystic ovary syndrome in women was associated with marked alterations of the tricarboxylic acid (TCA) cycle (Zhao et al., 2012).

Another important association identified in the present study is related to "Th1 and Th2 cell differentiation" pathway. T-Helper (Th) cells are, among others, responsible for modulating immune responses. Based on cytokine production, Th cells are classified into Th1 and Th2. Both Th1 and Th2 cells are regulated by progesterone, a hormone secreted by the female reproductive system and associated with establishment and maintenance of pregnancy. T-Helper 1-related cells appear to be associated with nonpregnancy and embryonic loss in cows (Hansen et al., 2004; Maeda et al., 2013). In addition, evidence suggests that Th1 and Th2 cells are differentially regulated by stress hormones, which might induce pro-inflammatory activities in certain tissues and may influence the onset and course of infectious, autoimmune/inflammatory, allergic, and neoplastic diseases (Elenkov and Chrousos, 1999). This pathway was associated with the cyclin-dependent ki- 
Table 6. Twenty-SNP windows that explained more than $1 \%$ of genetic variance (Var) for cystic ovaries (CYST), metritis (METR), and retained placenta (RETP) in Canadian Holstein dairy cows and the corresponding list of annotated genes within each window

\begin{tabular}{|c|c|c|c|c|c|}
\hline Trait & $\operatorname{Var}^{1}(\%)$ & BTA & Start (bp) & End (bp) & Genes $^{2}$ \\
\hline \multirow{4}{*}{ CYST } & 1.589 & 25 & $17,245,976$ & $18,590,810$ & CCP110, C16orf62, IQCK, ACSM5, ACSM1, ACSM4 \\
\hline & 1.531 & 25 & $34,663,848$ & $35,532,374$ & POR, MDH2, SRRM3, HSPB1, DTX2, UPK3B, \\
\hline & 1.199 & 21 & $65,803,314$ & $67,059,264$ & $\begin{array}{l}\text { CCNK, HHIPL1, CYP46A1, EML1, U1, EVL, bta-mir-342, YY1, bta- } \\
\text { mir-345 }\end{array}$ \\
\hline & 1.195 & 15 & $5,134,162$ & $6,310,157$ & DCUN1D5, MMP13, MMP8, MMP27, MMP20 \\
\hline \multirow{6}{*}{ METR } & 1.966 & 16 & $4,567,154$ & $6,385,951$ & $F C M R, \boldsymbol{P F} \boldsymbol{K} \boldsymbol{F} \mathbf{B} 2, C 4 B P B, C 4 B P A, C R 2, K C N T 2$ \\
\hline & 1.611 & 2 & 35,126 & $1,164,256$ & LGSN, NIPA1, NIPA2 \\
\hline & 1.323 & 29 & $41,166,786$ & $41,939,696$ & $\begin{array}{l}\text { BEST1, ASRGL1, U6atac, SCGB1A1, ROM1, METTL12, SNORA57, } \\
\text { UQCC3, GNG3, POLR2G, TAF6L, TMEM179B, SLC3A2 }\end{array}$ \\
\hline & 1.163 & 20 & $24,179,723$ & $25,463,818$ & SNORA17, COX8A, ARL15 \\
\hline & 1.160 & 28 & $1,135,437$ & $2,751,851$ & GALNT2, 5S_rRNA, OR5AS1, OR5D14 \\
\hline & 1.130 & 14 & $16,902,500$ & $18,000,539$ & MTSS1, TATDN1, TMEM65, ANXA13, KLHL38, FBXO32 \\
\hline \multirow{5}{*}{ RETP } & 1.436 & 16 & $44,176,019$ & $46,093,561$ & $\begin{array}{l}\text { U6, CTNNBIP1, CLSTN1, U6, 5S_rRNA, bta-mir-34a, U1, GPR157, U6, } \\
\text { RERE }\end{array}$ \\
\hline & 1.410 & 14 & $81,864,817$ & $83,027,085$ & - \\
\hline & 1.272 & 6 & $2,343,794$ & $3,505,409$ & NPY1R, NAF1, U6, BBS7, CCNA2 \\
\hline & 1.243 & 21 & $31,278,884$ & $33,475,697$ & $\begin{array}{l}\text { IREB2, HYKK, PSMA4, CHRNA5, UBE2Q2, FBXO22, SNORA3, } \\
\text { TMEM266, ISL2, RCN2, PSTPIP1, HMG20A }\end{array}$ \\
\hline & 1.227 & 10 & $44,733,798$ & $45,488,421$ & GNG2, C14orf166, PTGDR, PIF1, RBPMS2, OAZ2 \\
\hline
\end{tabular}

\footnotetext{
${ }^{1}$ Single-step genomic BLUP was used to obtain marker effects.
}

${ }^{2}$ Important candidate genes for each trait are shown in bold face. Any genes with start and stop positions fully or partially overlapping the window were also considered.

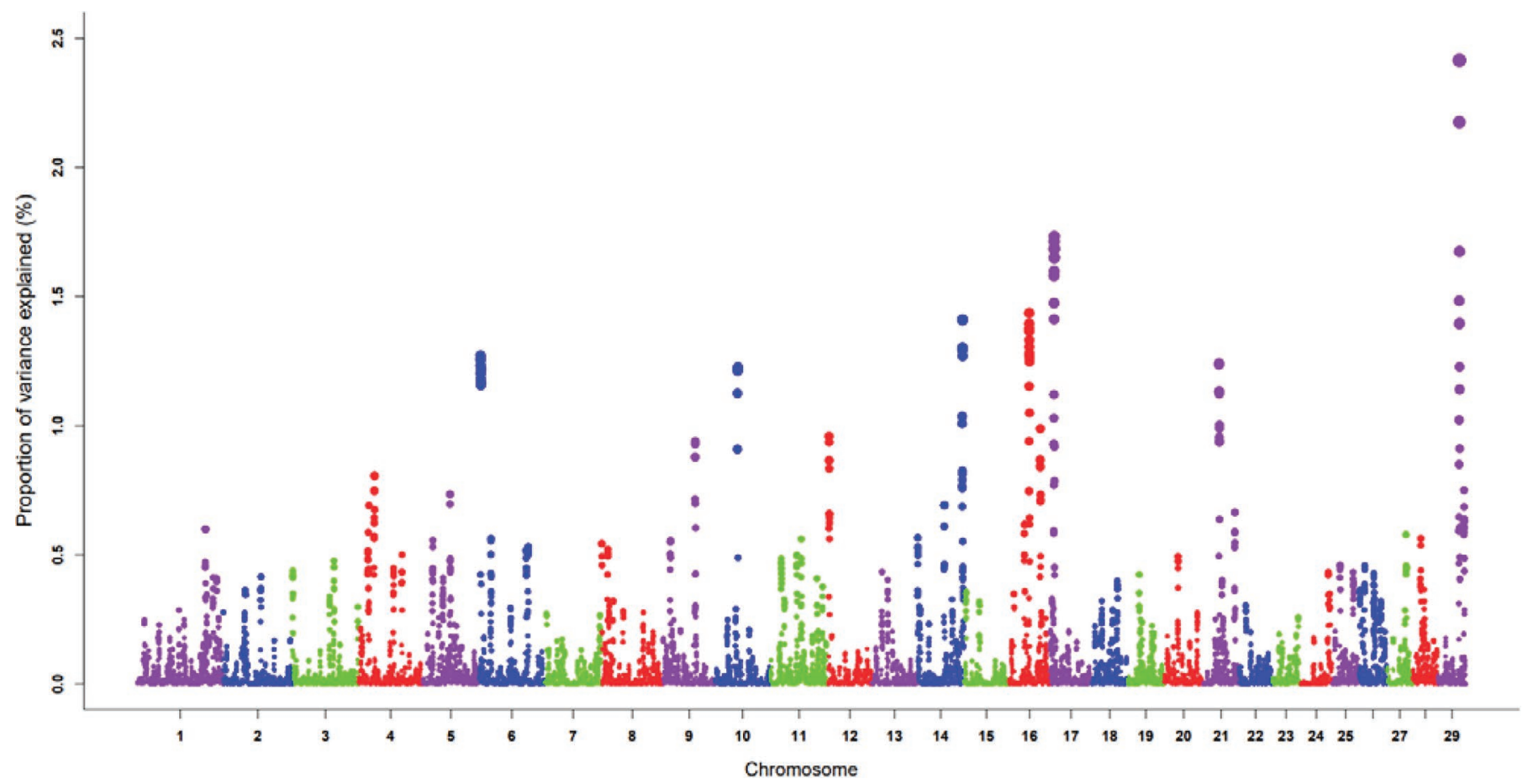

Figure 4. Manhattan plot for the proportion of genetic variance explained by the 20-SNP moving windows for retained placenta. 
Table 7. Pathways identified, associated enzymes, and associated genes for cystic ovaries (CYST), metritis (METR), and retained placenta (RETP) in the Kyoto Encyclopedia of Genes and Genomes (KEGG)

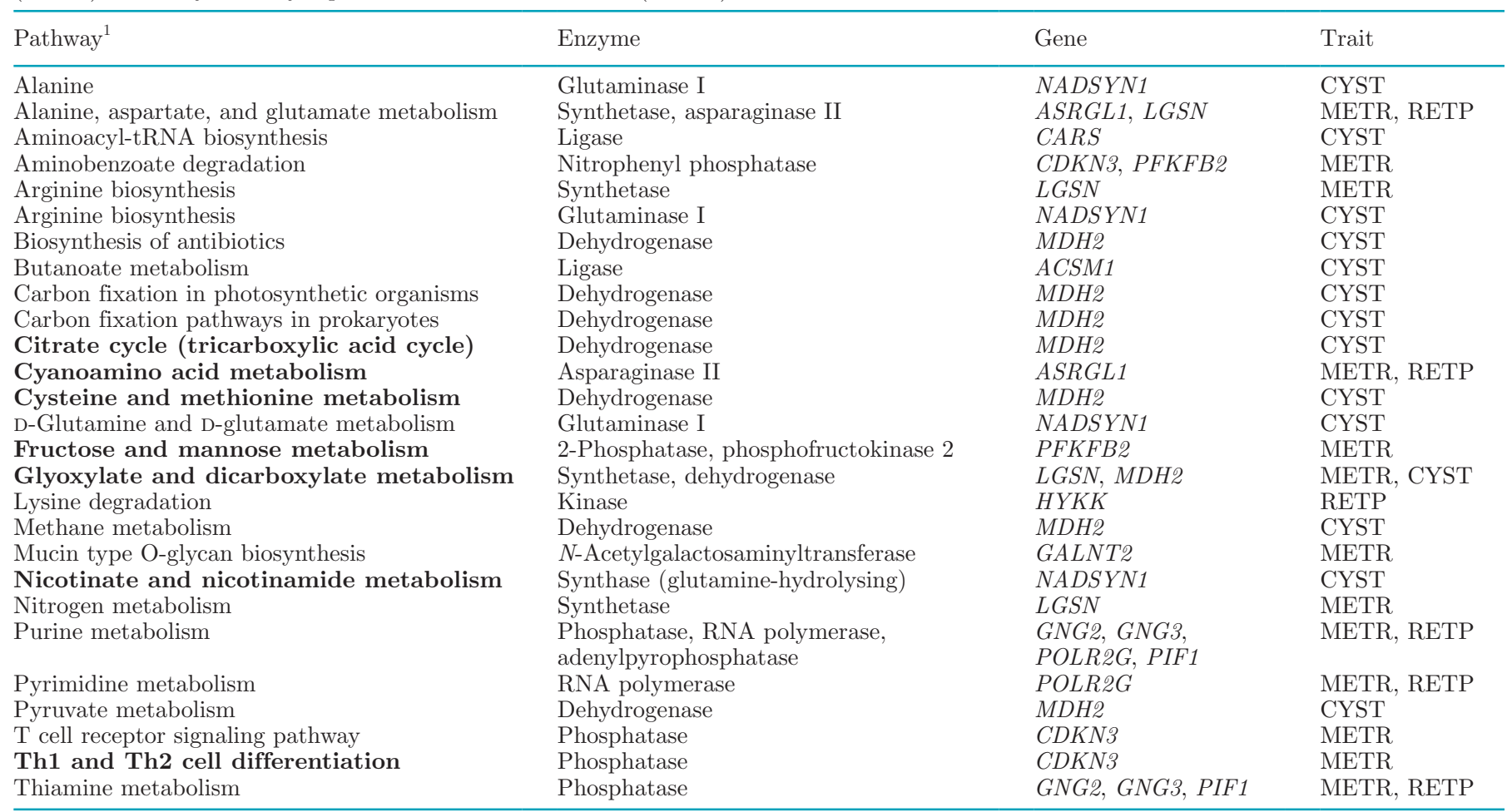

${ }^{1}$ Biological pathways known to be related to CYST, METR, or RETP are shown in bold.

nase inhibitor 3 gene (CDKN3), which may play a role in negative regulation of cell cycle in placenta in women (Mikheev et al., 2008).

In a similar manner, the "cyanoamino acid metabolism" pathway, which was significant for both METR and RETP, mediates inflammatory responses, cellular proliferation, cell movement, the cell cycle, and apoptosis in the bovine endometrium (Hailemariam et al., 2014). This pathway was associated with the ASRGL1 gene located on BTA29, which explained the highest amount of variation for RETP (2.4\%), followed by METR (1.32\%, Table 6). The "T cell receptor signaling pathway" is also related to immune response, inflammatory diseases and is associated with the "Th1 and Th2 cell differentiation" pathway in KEGG (Kanehisa and Goto, 2000; Kanehisa et al., 2016, 2017).

\section{CONCLUSIONS}

Despite the low heritability estimates observed for reproductive disorders (i.e., metritis, retained placenta, and cystic ovaries), a substantial increase in the theoretical reliability of EBV can be achieved by incorporating genomic information into evaluations through a single-step approach, especially when using multipletrait analysis. As genetic gains are cumulative over gen- erations, genetic progress is expected in the long term if continued genetic selection is implemented. High and positive (favorable) genetic correlations were found between retained placenta and metritis, implying that selection to improve one trait could lead to a positive response in the other. Genome-wide association studies using single-step GBLUP and functional analyses revealed biological pathways and genes associated with retained placenta, metritis, and cystic ovaries. These findings will contribute to increasing the accuracy of genomic predictions for these traits and, therefore, contribute to enhance the reproductive efficiency of dairy cattle herds.

\section{ACKNOWLEDGMENTS}

This research was supported in main part by Agriculture and Agri-Food Canada (Guelph, ON, Canada) and by additional contributions from the Dairy Farmers of Canada (Ottawa, ON, Canada), the Canadian Dairy Network (Guelph, ON, Canada), and the Canadian Dairy Commission (Ottawa, ON, Canada) under the Agri-Science Clusters Initiative. The authors thank Angela Cánovas (Department of Animal Biosciences, University of Guelph, Guelph, ON, Canada) for providing advice and support with the functional analyses. 
The first author is also grateful to CAPES (Brazilian Federal Agency for Support and Evaluation of Graduate Education, Brazil) for financial support.

\section{REFERENCES}

Aguilar, I., I. Misztal, D. L. Johnson, A. Legarra, S. Tsuruta, and T. J. Lawlor. 2010. Hot topic: A unified approach to utilize phenotypic, full pedigree, and genomic information for genetic evaluation of Holstein final score. J. Dairy Sci. 93:743-752. https://doi.org/10 $.3168 /$ jds.2009-2730.

Barreto Amaral Teixeira, D., G. A. F. Júnior, D. B. S. Silva, R. B. Costa, L. Takada, D. G. M. Gordo, T. Bresolin, R. Carvalheiro, F. Baldi, and L. G. Albuquerque. 2017. Genomic analysis of stayability in Nellore cattle. PLoS One 12:e0179076. https://doi.org/ 10.1371/journal.pone.0179076.

Beltman, M. E., N. Forde, P. Furney, F. Carter, J. F. Roche, P. Lonergan, and M. A. Crowe. 2010. Characterisation of endometrial gene expression and metabolic parameters in beef heifers yielding viable or non-viable embryos on day 7 after insemination. Reprod. Fertil. Dev. 22:987-999. https://doi.org/10.1071/RD09302.

Berry, D. P., N. C. Friggens, M. Lucy, and J. R. Roche. 2016. Milk production and fertility in cattle. Annu. Rev. Anim. Biosci. 4:269-290. https://doi.org/10.1146/annurev-animal-021815-111406.

Chen, C. Y., I. Misztal, I. Aguilar, S. Tsuruta, T. H. E. Meuwissen, S. E. Aggrey, T. Wing, and W. M. Muir. 2011. Genome-wide marker-assisted selection combining all pedigree phenotypic information with genotypic data in one step: An example using broiler chickens. J. Anim. Sci. 89:23-28. https://doi.org/10.2527/jas.2010 -3071 .

Chesnais, J. P., T. A. Cooper, G. R. Wiggans, M. Sargolzaei, J. E. Pryce, and F. Miglior. 2016. Using genomics to enhance selection of novel traits in North American dairy cattle. J. Dairy Sci. 99:2413-2427. https://doi.org/10.3168/jds.2015-9970.

Christensen, O. F., and M. S. Lund. 2010. Genomic prediction when some animals are not genotyped. Genet. Sel. Evol. 42:2. https:// doi.org/10.1186/1297-9686-42-2.

Dekkers, J. C. M. 2007. Prediction of response to marker-assisted and genomic selection using selection index theory. J. Anim. Breed. Genet. 124:331-341.

Dhakal, K., F. Tiezzi, J. S. Clay, and C. Maltecca. 2015. Inferring causal relationships between reproductive and metabolic health disorders and production traits in first-lactation US Holsteins using recursive models. J. Dairy Sci. 98:2713-2726. https://doi.org/ $10.3168 /$ jds.2014-8448.

Elenkov, I. J., and G. P. Chrousos. 1999. Stress hormones, Th1/Th2 patterns, pro/anti-inflammatory cytokines and susceptibility to disease. Trends Endocrinol. Metab. 10:359-368.

Feng, Z. 2014. A generalized quasi-likelihood scoring approach for simultaneously testing the genetic association of multiple traits. J. R. Stat. Soc. Ser. C Appl. Stat. 63:483-498. https://doi.org/10 $.1111 /$ rssc. 12038 .

Gonsette, R. E. 2008. Neurodegeneration in multiple sclerosis: The role of oxidative stress and excitotoxicity. J. Neurol. Sci. 274:48 53. https://doi.org/10.1016/j.jns.2008.06.029.

Götz, S., J. M. Garcia-Gomez, J. Terol, T. D. Williams, S. H. Nagaraj, M. J. Nueda, M. Robles, M. Talon, J. Dopazo, and A. Conesa. 2008. High-throughput functional annotation and data mining with the Blast2GO suite. Nucleic Acids Res. 36:3420-3435. https: //doi.org/10.1093/nar/gkn176.

Hailemariam, D., S. Ibrahim, M. Hoelker, M. Drillich, W. Heuwieser, C. Looft, M. U. Cinar, E. Tholen, K. Schellander, and D. Tesfaye. 2014. MicroRNA-regulated molecular mechanism underlying bovine subclinical endometritis. Reprod. Fertil. Dev. 26:898-913. https://doi.org/10.1071/RD13027.

Hansen, P. J., P. Soto, and R. P. Natzke. 2004. Mastitis and fertility in cattle-Possible involvement of inflammation or immune activation in embryonic mortality. Am. J. Reprod. Immunol. 51:294-301. https://doi.org/10.1111/j.1600-0897.2004.00160.x.
Hayes, B. 2013 Overview of statistical methods for genome-wide association studies (GWAS). Pages 149-170 in Genome-Wide Association Studies and Genomic Prediction. Methods in Molecular Biology (Methods and Protocols), Vol. 1019. C. Gondro, J. van der Werf, and B. Hayes, ed. Humana Press, Totowa, NJ.

Hayes, B. J., P. J. Bowman, A. C. Chamberlain, and M. E. Goddard. 2009. Invited review: Genomic selection in dairy cattle: Progress and challenges. J. Dairy Sci. 92:433-443.

Jamrozik, J., A. Koeck, G. J. Kistemaker, and F. Miglior. 2016. Multiple-trait estimates of genetic parameters for metabolic disease traits, fertility disorders, and their predictors in Canadian Holsteins. J. Dairy Sci. 99:1990-1998. https://doi.org/10.3168/jds 2015-10505.

Jamrozik, J., L. R. Schaeffer, and G. B. Jansen. 2000. Approximate accuracies of prediction from random regression models. Livest. Prod. Sci. 66:85-92.

Kanehisa, M., M. Furumichi, M. Tanabe, Y. Sato, and K. Morishima. 2017. KEGG: New perspectives on genomes, pathways, diseases and drugs. Nucleic Acids Res. 45:D353-D361.

Kanehisa, M., and S. Goto. 2000. KEGG: Kyoto Encyclopedia of Genes and Genomes. Nucleic Acids Res. 28:27-30.

Kanehisa, M., Y. Sato, M. Kawashima, M. Furumichi, and M. Tanabe. 2016. KEGG as a reference resource for gene and protein annotation. Nucleic Acids Res. 44:D457-D462.

Kelton, D. F., K. D. Lissemore, and R. E. Martin. 1998. Recommendations for recording and calculating the incidence of selected clinical diseases of dairy cattle. J. Dairy Sci. 81:2502-2509. https://doi .org/10.3168/jds.S0022-0302(98)70142-0.

Koeck, A., F. Miglior, D. F. Kelton, and F. S. Schenkel. 2012. Health recording in Canadian Holsteins: Data and genetic parameters. J Dairy Sci. 95:4099-4108. https://doi.org/10.3168/jds.2011-5127.

Larmer, S. G., M. Sargolzaei, and F. S. Schenkel. 2014. Extent of linkage disequilibrium, consistency of gametic phase, and imputation accuracy within and across Canadian dairy breeds. J. Dairy Sci. 97:3128-3141. https://doi.org/10.3168/jds.2013-6826.

Legarra, A., I. Aguilar, and I. Misztal. 2009. A relationship matrix including full pedigree and genomic information. J. Dairy Sci. 92:4656-4663. https://doi.org/10.3168/jds.2009-2061.

Legarra, A., O. F. Christensen, I. Aguilar, and I. Misztal. 2014. Singlestep, a general approach for genomic selection. Livest. Sci. 166:5465. https://doi.org/10.1016/j.livsci.2014.04.029.

Legarra, A., C. Robert-Granié, E. Manfredi, and J. M. Elsen. 2008 Performance of genomic selection in mice. Genetics 180:611-618.

Lourenco, D. A. L., B. O. Fragomeni, H. L. Bradford, I. R. Menezes, J. B. S. Ferraz, I. Aguilar, S. Tsuruta, and I. Misztal. 2017. Implications of SNP weighting on single-step genomic predictions for different reference population sizes. J. Anim. Breed. Genet. 134:463-471. https://doi.org/10.1111/jbg.12288.

Mackey, D. R., A. W. Gordon, M. A. McCoy, M. Verner, and C. S. Mayne. 2007. Associations between genetic merit for milk production and animal parameters and the fertility performance of dairy cows. Animal 1:29-43. https://doi.org/10.1017/ S1751731107257921.

Maeda, Y., H. Ohtsuka, M. Tomioka, and M. Oikawa. 2013. Effect of progesterone on Th1/Th2/Th17 and Regulatory T cell-related genes in peripheral blood mononuclear cells during pregnancy in cows. Vet. Res. Commun. 37:43-49. https://doi.org/10.1007/ s11259-012-9545-7.

Martínez, Y., X. Li, G. Liu, P. Bin, W. Yan, D. Más, M. Valdivié, C. A. A. Hu, W. Ren, and Y. Yin. 2017. The role of methionine on metabolism, oxidative stress, and diseases. Amino Acids 49:20912098. https://doi.org/10.1007/s00726-017-2494-2.

Medeiros de Oliveira Silva, R., N. B. Stafuzza, B. D. O. Fragomeni, G. M. Ferreira De Camargo, T. M. Ceacero, J. N. S. G. Cyrillo, F. Baldi, A. A. Boligon, M. E. Z. Mercadante, D. L. Lourenco, I Misztal, and L. G. De Albuquerque. 2017. Genome-wide association study for carcass traits in an experimental Nelore cattle population. PLoS One 12:e0169860. https://doi.org/10.1371/journal .pone.0169860.

Melo, T. P., G. M. F. de Camargo, L. G. de Albuquerque, and R. Carvalheiro. 2017. Genome-wide association study provides strong 
evidence of genes affecting the reproductive performance of Nellore beef cows. PLoS One 12:e0178551. https://doi.org/10.1371/ journal.pone.0178551.

Meuwissen, T., B. Hayes, and M. Goddard. 2016. Genomic selection: A paradigm shift in animal breeding. Anim. Front. 6:6. https://doi .org/10.2527/af.2016-0002.

Mikheev, A. M., T. Nabekura, A. Kaddoumi, T. K. Bammler, R. Govindarajan, M. F. Hebert, and J. D. Unadkat. 2008. Profiling gene expression in human placentae of different gestational ages: An OPRU* network and UW SCOR study. Reprod. Sci. 15:866-877. https://doi.org/10.1177/1933719108322425.

Misztal, I., A. Legarra, and I. Aguilar. 2009. Computing procedures for genetic evaluation including phenotypic, full pedigree, and genomic information. J. Dairy Sci. 92:4648-4655. https://doi.org/10 .3168/jds.2009-2064.

Misztal, I., S. Tsuruta, T. Strabel, B. Auvray, T. Druet, and D. Lee. 2002. BLUPF90 and related programs (BGF90). Communication No. 28-07 in Proc. 7th World Congr. Genet. Appl. Livest. Prod., Montpellier, France. Editions Quae, Montpellier, France.

Nagamine, Y., S. A. Knott, P. M. Visscher, and C. S. Haley. 2002. Simple deterministic identity-by-descent coefficients and estimation of QTL allelic effects in full and half sibs. Genet. Res. 80:237-243. https://doi.org/10.1017/s0016672302005918.

Neuenschwander, T. F.-O., F. Miglior, J. Jamrozik, O. Berke, D. F. Kelton, and L. R. Schaeffer. 2012. Genetic parameters for producer-recorded health data in Canadian Holstein cattle. Animal 6:571-578.

Ospina, P. A., D. V. Nydam, T. Stokol, and T. R. Overton. 2010. Evaluation of non-esterified fatty acids and $\beta$-hydroxybutyrate in transition dairy cattle in the northeastern United States: Critical thresholds for prediction of clinical diseases. J. Dairy Sci. 93:546554. https://doi.org/10.3168/jds.2009-2277.

Parker Gaddis, K. L., J. B. Cole, J. S. Clay, and C. Maltecca. 2012. Incidence validation and relationship analysis of producer-recorded health event data from on-farm computer systems in the United States. J. Dairy Sci. 95:5422-5435. https://doi.org/10.3168/jds .2012-5572.

Parker Gaddis, K. L., J. B. Cole, J. S. Clay, and C. Maltecca. 2014. Genomic selection for producer-recorded health event data in US dairy cattle. J. Dairy Sci. 97:3190-3199. https://doi.org/10.3168/ jds.2013-7543.

Philipsson, J., and B. Lindhé. 2003. Experiences of including reproduction and health traits in Scandinavian dairy cattle breeding programmes. Livest. Prod. Sci. 83:99-112. https://doi.org/10.1016/ S0301-6226(03)00047-2.

Pritchard, T., M. Coffey, R. Mrode, and E. Wall. 2013. Genetic parameters for production, health, fertility and longevity traits in dairy cows. Animal 7:34-46. https://doi.org/10.1017/ S1751731112001401.

Pryce, J. E., S. Bolormaa, A. J. Chamberlain, P. J. Bowman, K. Savin, M. E. Goddard, and B. J. Hayes. 2010. A validated genome-wide association study in 2 dairy cattle breeds for milk production and fertility traits using variable length haplotypes. J. Dairy Sci. 93:3331-3345. https://doi.org/10.3168/jds.2009-2893.

Sargolzaei, M., J. P. Chesnais, and F. S. Schenkel. 2014. A new approach for efficient genotype imputation using information from relatives. BMC Genomics 15:478. https://doi.org/10.1186/1471 $-2164-15-478$.

Schaeffer, L. R. 1984. Sire and cow evaluation under multiple trait models. J. Dairy Sci. 67:1567-1580. https://doi.org/10.3168/jds .S0022-0302(84)81479-4.

Schaeffer, L. R. 2006. Strategy for applying genome wide selection in dairy cattle. J. Anim. Breed. Genet. 123:218-223.

Sordillo, L. M., and S. L. Aitken. 2009. Impact of oxidative stress on the health and immune function of dairy cattle. Vet. Immunol. Immunopathol. 128:104-109. https://doi.org/10.1016/j.vetimm.2008 .10.305.

Sorensen, D., and D. Gianola. 2002. Likelihood, Bayesian and MCMC Methods in Quantitative Genetics, Springer-Verlag, New York, NY.
Sun, C., P. Madsen, M. S. Lund, Y. Zhang, U. S. Nielsen, and G. Su. 2010. Improvement in genetic evaluation of female fertility in dairy cattle using multiple-trait models including milk production traits. J. Anim. Sci. 88. https://doi.org/10.2527/jas.2009-1912.

Tetens, J., T. Seidenspinner, N. Buttchereit, and G. Thaller. 2013. Whole-genome association study for energy balance and fat/protein ratio in German Holstein bull dams. Anim. Genet. 44:1-8. https://doi.org/10.1111/j.1365-2052.2012.02357.x.

Tsuruta, S., D. A. L. Lourenco, I. Misztal, and T. J. Lawlor. 2017. Genomic analysis of cow mortality and milk production using a threshold-linear model. J. Dairy Sci. 100:7295-7305. https://doi .org/10.3168/jds.2017-12665.

Vallejo, R. L., T. D. Leeds, G. Gao, J. E. Parsons, K. E. Martin, J. P. Evenhuis, B. O. Fragomeni, G. D. Wiens, and Y. Palti. 2017. Genomic selection models double the accuracy of predicted breeding values for bacterial cold water disease resistance compared to a traditional pedigree-based model in rainbow trout aquaculture. Genet. Sel. Evol. 49:17. https://doi.org/10.1186/s12711-017-0293 -6 .

Van Doormaal, B. 2009. Health data recording in Canada. Accessed July 26, 2017. https://www.cdn.ca/document.php?id=160.

VanRaden, P. M. 2008. Efficient methods to compute genomic predictions. J. Dairy Sci. 91:4414-4423. https://doi.org/10.3168/jds 2007-0980.

Vukasinovic, N., N. Bacciu, C. A. Przybyla, P. Boddhireddy, and S. K. DeNise. 2017. Development of genetic and genomic evaluation for wellness traits in US Holstein cows. J. Dairy Sci. 100:428-438. https://doi.org/10.3168/jds.2016-11520.

Walsh, S. W., E. J. Williams, and A. C. O. Evans. 2011. A review of the causes of poor fertility in high milk producing dairy cows. Anim. Reprod. Sci. 123:127-138. https://doi.org/10.1016/j anireprosci.2010.12.001

Wang, H., I. Misztal, I. Aguilar, A. Legarra, R. L. Fernando, Z. Vitezica, R. Okimoto, T. Wing, R. Hawken, and W. M. Muir. 2014 Genome-wide association mapping including phenotypes from relatives without genotypes in a single-step (ssGWAS) for 6-week body weight in broiler chickens. Front. Genet. 5:134. https://doi .org/10.3389/fgene.2014.00134.

Wang, H., I. Misztal, I. Aguilar, A. Legarra, and W. M. Muir. 2012. Genome-wide association mapping including phenotypes from relatives without genotypes. Genet. Res. (Camb.) 94:73-83. https:// doi.org/10.1017/S0016672312000274.

Wu, P., Q. Yang, K. Wang, J. Zhou, J. Ma, Q. Tang, L. Jin, W. Xiao, A. Jiang, Y. Jiang, L. Zhu, X. Li, and G. Tang. 2018. Single step genome-wide association studies based on genotyping by sequence data reveals novel loci for the litter traits of domestic pigs. Genomics 110:171-179. https://doi.org/10.1016/j.ygeno.2017.09.009.

$\mathrm{Xu}, \mathrm{S} .2003$. Estimating polygenic effects using markers of the entire genome. Genetics 163:789-801. https://doi.org/10.1534/genetics .107 .081190

Zhang, X., D. Lourenco, I. Aguilar, A. Legarra, and I. Misztal. 2016. Weighting strategies for single-step genomic BLUP: An iterative approach for accurate calculation of GEBV and GWAS. Front. Genet. 7:151.https://doi.org/10.3389/fgene.2016.00151.

Zhang, Z., J. Liu, X. Ding, P. Bijma, D. J. de Koning, and Q. Zhang, 2010. Best linear unbiased prediction of genomic breeding values using a trait-specific marker-derived relationship matrix. PLoS One 5:1-8. https://doi.org/10.1371/journal.pone.0012648.

Zhao, H., L. Sui, K. Miao, L. An, D. Wang, Z. Hou, R. Wang, M. Guo, Z. Wang, J. Xu, Z. Wu, and J. Tian. 2015. Comparative analysis between endometrial proteomes of pregnant and non-pregnant ewes during the peri-implantation period. J. Anim. Sci. Biotechnol. 6:18. https://doi.org/10.1186/s40104-015-0017-0.

Zhao, Y., L. Fu, R. Li, L.-N. Wang, Y. Yang, N.-N. Liu, C.-M. Zhang, Y. Wang, P. Liu, B.-B. Tu, X. Zhang, and J. Qiao. 2012. Metabolic profiles characterizing different phenotypes of polycystic ovary syndrome: Plasma metabolomics analysis. BMC Med. 10:153. https://doi.org/10.1186/1741-7015-10-153. 